\title{
The Roots of the Obesity Boom. The Relationship Between Overweight and Educational Level Among Dutch Men, 1950-1979
}

By Björn Quanjer and Kristina Thompson

To cite this article: Quanjer, B. \& Thompson, K. (2021). The Roots of the Obesity Boom. The Relationship Between Overweight and Educational Level Among Dutch Men, 1950-1979. Historical Life Course Studies, 10, 124-129. https:// doi.org/10.51964/hlcs9580

\section{HISTORICAL LIFE COURSE STUDIES}

Not Like Everybody Else.

Essays in Honor of Kees Mandemakers

VOLUME 10, SPECIAL ISSUE 3

2021

GUEST EDITORS

Hilde Bras

Jan Kok

Richard L. Zijdeman 


\section{HISTORICAL LIFE COURSE STUDIES}

Historical Life Course Studies is the electronic journal of the European Historical Population Samples Network (EHPSNet). The journal is the primary publishing outlet for research involved in the conversion of existing European and nonEuropean large historical demographic databases into a common format, the Intermediate Data Structure, and for studies based on these databases. The journal publishes both methodological and substantive research articles.

\section{Methodological Articles}

This section includes methodological articles that describe all forms of data handling involving large historical databases, including extensive descriptions of new or existing databases, syntax, algorithms and extraction programs. Authors are encouraged to share their syntaxes, applications and other forms of software presented in their article, if pertinent, on the openjournals website.

\section{Research articles}

This section includes substantive articles reporting the results of comparative longitudinal studies that are demographic and historical in nature, and that are based on micro-data from large historical databases.

Historical Life Course Studies is a no-fee double-blind, peer-reviewed open-access journal supported by the European Science Foundation (ESF, http://www.esf.org), the Scientific Research Network of Historical Demography (FWO Flanders, http://www.historicaldemography.be) and the International Institute of Social History Amsterdam (IISH, http://socialhistory.org/). Manuscripts are reviewed by the editors, members of the editorial and scientific boards, and by external reviewers. All journal content is freely available on the internet at https://openjournals.nl/index.php/hlcs.

\section{Co-Editors-In-Chief:}

Paul Puschmann (Radboud University) \& Luciana Quaranta (Lund University)

hislives@kuleuven.be

The European Science Foundation (ESF) provides a platform for its Member Organisations to advance science and explore new directions for research at the European level. Established in 1974 as an independent non-governmental organisation, the ESF currently serves 78 Member Organisations across 30 countries. EHPS-Net is an ESF Research Networking Programme.

The European Historical Population Samples Network (EHPS-net) brings together scholars to create a common format for databases containing non-aggregated information on persons, families and households. The aim is to form an integrated and joint interface between many European and non-European databases to stimulate comparative research on the micro-level.

Visit: http://www.ehps-net.eu.
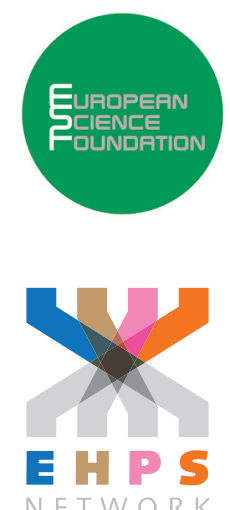


\title{
The Roots of the Obesity Boom \\ The Relationship Between Overweight and Educational Level Among Dutch Men, 1950-1979
}

\author{
Björn Quanjer \\ Radboud University Nijmegen \\ Kristina Thompson \\ VU Amsterdam
}

\begin{abstract}
While in modern, high-income populations, obesity is associated with being from a low socio-economic background, this may not have always been the case. We test the relationship between obesity and educational level (as a proxy for socio-economic status) in a historical cohort of Dutch military conscripts, from the conscription years 1950-1979. We find that in the 1950s cohort, being in tertiary education was significantly associated with an increased likelihood of being overweight. In contrast, in the 1970s cohort, being in tertiary education was significantly associated with a decreased likelihood of being overweight. We find evidence that the prevalence of obesity remained broadly similar among more highly educated men, while it increased among men of a lower educational level. This likely contributed to the overall rise in the obesity rate. Our findings echo other studies that find a crossover in education's relationship to BMI as populations become wealthier and obesity rates rise.
\end{abstract}

Keywords: Obesity, Height, BMI, Weight, The Netherlands, Anthropometric history

e-ISSN: $\quad$ 2352-6343

DOI article: $\quad$ https://doi.org/10.51964/hlcs9580

The article can be downloaded from here.

(C) 2021, Quanjer, Thompson

This open-access work is licensed under a Creative Commons Attribution 4.0 International License, which permits use, reproduction \& distribution in any medium for non-commercial purposes, provided the original author(s) and source are given credit. See http://creativecommons.org/licenses/. 


\section{INTRODUCTION}

An increasingly overweight/obese population is one of the biggest public health challenges today: obesity $(\mathrm{BMI}>30)$ and overweight (BMI > 25) are a risk factor for a host of chronic diseases (stroke, heart disease, diabetes, musculoskeletal disorders, certain cancers, etc.) (Devaux, Sassi, Church, Cecchini, \& Borgonovi, 2011). In virtually all high-income countries, obesity rates have risen sharply over the past five decades, with the global obesity rate tripling since 1975 . As of 2016,650 million people worldwide are obese, with a further 1.9 billion adults who are overweight (World Health Organization, 2020). We focus this paper on the Netherlands, which has experienced similar trends. Since 1981, the obesity rate has doubled: $14 \%$ of Dutch adults are obese, with a further $36 \%$ being overweight as of 2018, meaning that $50 \%$ of the adult population is either overweight or obese (Centraal Bureau voor de Statistiek, 2019).

While the rapid increase in obesity rates in high-income countries is a relatively recent phenomenon, its roots can be traced back earlier in the 20th century. Komlos, Breitfelder, and Sunder (2009) argue that this shift began in the mid-century in high-income countries, and is a by-product of nutritional, technological, and cultural shifts. Briefly, these shifts include: increased television consumption, greater short-distance use of automobiles, a broad move toward service economies, and an increased uptake of higher-calorie foods. This has led to an excess in dietary consumption as lifestyles have become more sedentary (Komlos et al., 2009).

Further, the socio-economic distribution of those who are overweight/obese has changed over the course of the 20th century: while obesity is widespread in high-income countries, it is more prevalent in lower socioeconomic status (SES) groups, and may exacerbate and reproduce other forms of socio-economic inequalities (Devaux et al., 2011). There is also evidence that as countries become wealthier, obesity transitions from a relatively marginal problem of the wealthy to a more widespread problem of the poor. Research into this relationship is currently very limited, and rarely with representative samples. However, the relationship has been demonstrated with modern global data in Templin, Hashiguchi, Thomson, Dieleman, and Bendavid (2019), and with historical Swiss data in Staub, Rühli, Woitek, and Pfister (2010). We add to this literature by examining education as a proxy for SES. We use a historical cohort of Dutch conscripts to better illustrate how and to what extent the relationship between obesity and education changes over time.

\section{METHODS}

To accomplish this, we use a sample of Dutch military conscripts, from the conscription years 1950-1979 (and birth years 1930-1959). The starting point of our sample is the Historical Sample of the Netherlands (HSN), which only goes up to birth year 1922. To examine a 20th-century cohort, we used a random sample of male HSN research persons (RPs), and located their sons' conscription records. This forms part of the Male Kin Heights Database (Mandemakers, 2019). The sample covers the entire country, except the provinces of Groningen and Zeeland. We start our sample with conscription year 1950 (birth year 1930). Complete weight and educational information is available from conscription year 1933 onward, but we elect to use conscription year 1950 as our sample's starting point. In the 1930s, there was minimal variance in both BMI and educational outcomes, because both being overweight (1.6\%) and going to tertiary education (1.7\%) were very rare. In the 1940s education was frequently not recorded, and BMIs were likely strongly affected by the Second World War and the Hongerwinter (the famine of 1944-45). We end our sample in 1979, due to data insufficiency in later cohorts. This gives us a sample of 3,718 RPs who were conscripted between 1950 and 1979.

The likelihood of having a body mass index (BMI) over 25 (widely considered to be the threshold of being overweight) is our outcome. Because obesity was exceedingly rare in our sample, we only refer to and calculate the likelihood of being overweight, not obese. BMI is calculated as body weight in kilograms divided by height in meters squared. Our key predictor is education, which is coded as: primary (lower education until age 12/13) education; secondary low (lower trade school, until age 15); secondary high (higher trade school, until age 17); tertiary (enrolled in a bachelor's degree or higher), and unknown educational level.

To test the association of educational outcomes with the likelihood of being overweight, we first graphically examine the relationship between education and having a BMI in the overweight range. For this figure, we combine RPs with only primary education or secondary lower education as the lower-educated group and combined secondary high and tertiary as the higher-educated group. Then, we statistically test the relationship between education and being overweight using logistic regressions. Because both education 
and BMI have been shown to increase over time, we expect that birth cohort is an effect modifier in the relationship between education and the likelihood of being overweight/obese. We therefore present four types of models: unadjusted but stratified by conscription cohort (Model 1); unadjusted using the full sample (Model 2); adjusted for period using the full sample (Model 3); and adjusted and interacted with period using the full sample (Model 4).

\section{RESULTS}

Figure 1 shows the percentage of RPs within each group that was overweight per decade. We find that the share of overweight RPs in the higher educated group remained relatively stable ( $6 \%$ in the 1950 s compared to $4 \%$ in the 1970s), whereas the lower educated group sees a sharp increase in the share of overweight RPs ( $2 \%$ in the 1950 s compared to $10 \%$ in the 1970s). It is also worth noting that the percentage of overweight and higher-educated people increased over our research period. Overweight increased from $3 \%$ in the 1950 s to $8 \%$ In the 1970s in our sample. Similarly, the share of RPs enrolled in tertiary education was $2.3 \%$ in the 1950 s cohort, and rose to $7.6 \%$ in the 1970 s cohort.

Figure 1 Share of overweight people per educational group per conscription decade

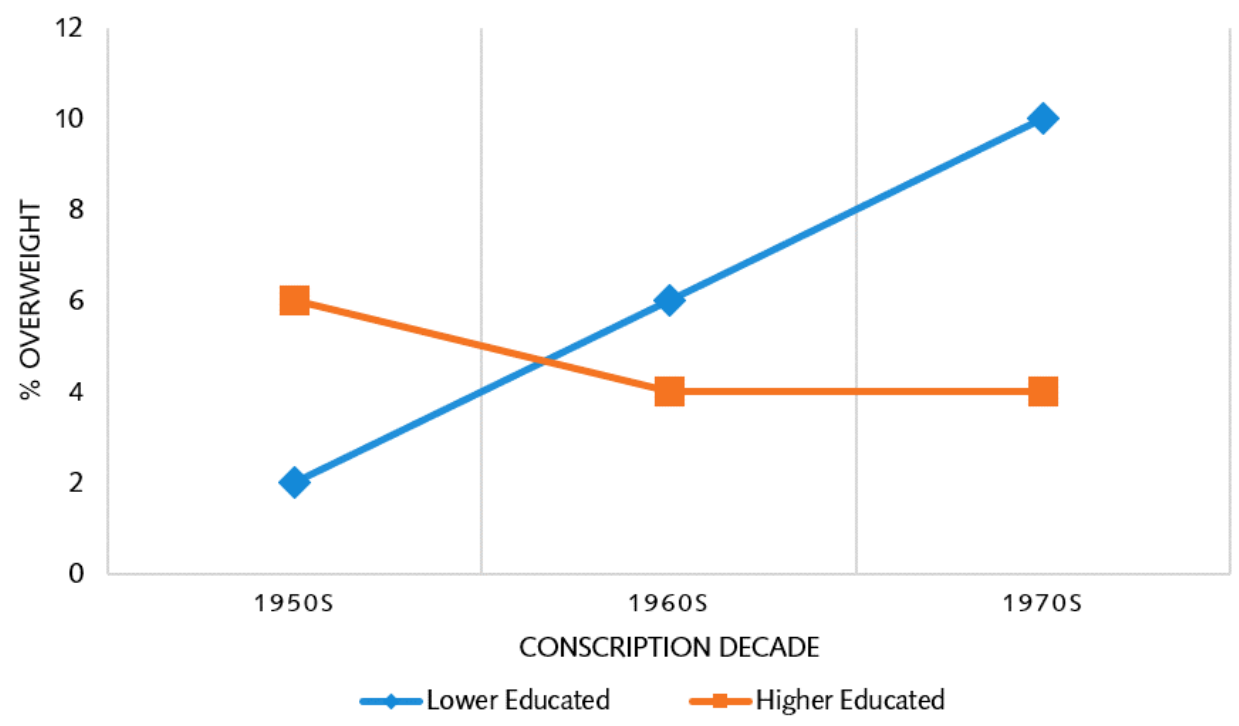

Table 1 shows the results of the logistic regressions. First, examining Model 1, we find an increased probability of being overweight for RPs who obtained the highest educational level in the 1950s. In the 1960s cohort, we do not find significant differences among educational levels. The 1970s cohort was a mirror image of the 1950s cohort: in this decade, RPs with a higher educational background tended to be overweight less frequently than those in our reference category (secondary low).

In Model 2, we do not find any effect of educational level on the likelihood of being overweight. Taking into account that we find that the effect of education on the likelihood of being obese differs by cohort, this result provides a further indication that the relationship is not constant over time. In Model 3, we find that the likelihood of being overweight increased successively over cohorts. In Model 4, we also find that the likelihood of being overweight increased by cohort. Importantly, the difference in effect of educational level per decade is significant. This indicates that a higher educational level was associated with an increased likelihood of being overweight in the 1950s and a reduced likelihood of being overweight in the 1970s. 
Table 1

Logistic regression of the effect of education on the likelihood of being overweight (BMI > 25). Stratified by, controlled for, and interacted with conscription decade

\begin{tabular}{|c|c|c|c|c|c|c|c|c|c|c|c|c|}
\hline \multirow[b]{3}{*}{ Education } & \multicolumn{6}{|c|}{ Model 1} & \multirow{2}{*}{\multicolumn{2}{|c|}{$\begin{array}{c}\text { Model } 2 \\
\text { Full sample }\end{array}$}} & \multirow{2}{*}{\multicolumn{2}{|c|}{$\begin{array}{c}\text { Model } 3 \\
\text { Full sample }\end{array}$}} & \multirow{2}{*}{\multicolumn{2}{|c|}{$\begin{array}{c}\text { Model } 4 \\
\text { Full sample }\end{array}$}} \\
\hline & \multicolumn{2}{|c|}{1950} & \multicolumn{2}{|c|}{1960} & \multicolumn{2}{|c|}{1970} & & & & & & \\
\hline & OR & $\mathrm{Cl}$ & OR & $\mathrm{Cl}$ & OR & $\mathrm{Cl}$ & OR & $\mathrm{Cl}$ & OR & $\mathrm{Cl}$ & OR & $\mathrm{Cl}$ \\
\hline Primary & 0.83 & $0.30-2.12$ & 1.62 & $0.80-3.19$ & 0.33 & $0.05-1.13$ & 0.74 & $0.44-1.18$ & 0.90 & $0.53-1.45$ & 0.83 & $0.30-2.12$ \\
\hline Secondary low & Ref. & & Ref. & & Ref. & & Ref. & & Ref. & & Ref. & \\
\hline Secondary high & 1.73 & $0.59-4.64$ & 0.89 & $0.37-1.95$ & 0.40 & $0.16-0.88$ & 0.80 & $0.47-1.30$ & 0.75 & $0.44-1.22$ & 1.73 & $0.59-4.64$ \\
\hline Tertiary & 6.20 & $1.32-22.01$ & 0.36 & $0.02-1.76$ & 0.20 & $0.01-0.97$ & 0.75 & $0.26-1.73$ & 0.66 & $0.23-1.52$ & 6.20 & $1.32-22.01$ \\
\hline Unknown & 1.96 & $0.10-10.88$ & 2.53 & $0.71-7.12$ & 0.40 & $0.02-2.02$ & 1.46 & $0.55-3.23$ & 1.37 & $0.51-3.05$ & 1.96 & $0.10-10.88$ \\
\hline \multicolumn{13}{|l|}{ Cohort } \\
\hline $1950 \mathrm{~s}$ & & & & & & & & & Ref. & & Ref. & \\
\hline $1960 s$ & & & & & & & & & 1.87 & $1.17-3.05$ & 1.96 & $0.96-4.22$ \\
\hline $1970 s$ & & & & & & & & & 2.62 & $1.58-4.38$ & 4.43 & $2.26-9.37$ \\
\hline \multicolumn{13}{|l|}{ Interactions } \\
\hline 1960s*Primary & & & & & & & & & & & 1.96 & $0.60-6.57$ \\
\hline 1970s*Primary & & & & & & & & & & & 0.40 & $0.05-2.00$ \\
\hline 1960s*Secondary high & & & & & & & & & & & 0.51 & $0.14-1.95$ \\
\hline 1970s*Secondary high & & & & & & & & & & & 0.23 & $0.06-0.88$ \\
\hline 1960s*Tertiary & & & & & & & & & & & 0.06 & $0.00-0.55$ \\
\hline 1970s*Tertiary & & & & & & & & & & & 0.03 & $0.00-0.30$ \\
\hline 1960s*Unknown & & & & & & & & & & & 1.29 & $0.15-28.1$ \\
\hline 1970s*Unknown & & & & & & & & & & & 0.20 & $0.01-5.73$ \\
\hline
\end{tabular}

Note: Significant odds ratios $(O R) P<0.10$ are in bold and in dark grey (higher chance of being overweight) and light grey (lower chance of being overweight). 


\section{DISCUSSION AND CONCLUSION}

We find clear evidence of a 'cross-over' in the relationship between educational level and being overweight. The prevalence of overweight people was comparatively minimal in the mid-20th century, and largely confined to higher-educated groups. Overweight had become more widespread, and an issue of lowereducated groups, by the 1970s. While overweight/obesity rates reached epidemic proportions in the last decades of the 20th century, we find evidence that its seeds were planted in earlier decades.

However, it is possible that we are detecting a spurious correlation between $\mathrm{BMI}$ and educational level. We will therefore consider various ways that this may be the case. First, while average BMI increased over our research period, so did average height. Did these taller statures result in a higher BMI? As lower educated groups experienced a stronger secular trend in height than higher-educated groups, the gap in average heights between these two groups lessened over our research period. Could that explain our results? To check this, we tested the relationship between height and BMI in a linear regression and height and being overweight in a logistic regression and found no significant effect. It does not appear that the secular trend in height is related to changing relationship between education and overweight that we observe.

Further, we may not be measuring the relationship between adult BMI and terminal educational outcomes, but rather measuring this relationship at various points during development. Our measurement of BMI is in all likelihood not that of terminal adults, as BMI tends to increase for men until age 25 (van Wieringen, 1972). It is also possible that education is related to age, with those who have attained or are in the process of attaining higher levels of education reporting at later ages for conscription. We find some evidence for this, because age is not entirely evenly distributed across educational groups. On average, those in the lowest educational group are 60 days younger at their conscription examinations than those in the highest educational group, and this difference is significant. However, including age at conscription as a covariate does not markedly change the results of our models, and age at conscription itself is not a significant predictor of being overweight. There is one exception to this: the likelihood of being overweight for RPs in tertiary education in the 1950s cohort is smaller when controlling for age at conscription. It appears that, in the 1950s, higher-educated RPs were conscripted at slightly older ages, thereby contributing to the larger likelihood of being in tertiary education and overweight among this cohort. However, even controlling for age, we still see that RPs in tertiary education have a much higher likelihood of being overweight.

Another potential problem in our framing of our analysis is reverse causality. Other studies have noted the possibility that it may not be lower educational attainment contributing to higher rates of overweight/obesity, and may instead be overweight/obesity contributing to lower educational opportunities (Devaux et al., 2011). Evidence for this comes from the fact that teachers are more likely to promote students with normal or lower BMls to higher levels of education, and being less likely to do so for students with higher BMIs (Devaux et al., 2011). Indeed, BMl is prone to rapid change, due to change in weight, whereas education is cumulative throughout development. Our study cannot distinguish the direction of the relationship between educational outcomes and the likelihood of being overweight, as height, weight and educational level are measured contemporaneously. Despite similar problems in determining directionality, other studies on the topic have similarly framed overweight/obesity as an outcome of being from a lower SES background (Devaux et al., 2011; Templin et al., 2019). Furthermore, it is implausible that overweight's influence on educational outcomes switched direction in the short time span of our study. There is existing research in support of the contrary: as outlined in Komlos et al. (2009), the sweeping environmental shifts of the mid-20th century are the likely culprits of the change in influence of education (as a proxy for SES) on the likelihood of being overweight.

But what could explain this cross-over in the relationship between the two? Differential access to food could be responsible. Key to this assumption is the relationship between SES and educational level. In the 1950s, being overweight was perhaps not financially possible for those from lower-SES backgrounds (and therefore lower educational levels), whereas it was for those from higher-SES backgrounds (and therefore higher educational levels). With the booming postwar economy and increased availability of cheap, highcalorie foods in the later cohorts, there were increased possibilities to become overweight for the entire socio-economic (and educational) spectrum. By the end of our research period, we already see that being from a lower educational background was associated with an increased likelihood of being overweight, likely due to greater class-based practices of eating higher-calorie fast foods. However, it is worth noting that the correlation between RP's father's occupational status (our best available proxy of economic conditions in early life) and RP's educational level was relatively weak. This indicates that there was significant social mobility regarding education, whereby RPs could rise or fall according to their own capabilities and/or achievements. 
In short, RPs had some influence over their own educational outcomes, and consequently their own BMIs. In this way, we can conceptualize education as, a trend that increased over our research period, conveying knowledge and opportunities to prevent overweight.

In sum, we find evidence that the seed of the obesity epidemic lies with the boom of overweight among lower educated individuals from the mid-20th century onwards. While the overweight/obesity epidemic became more visible — and was more frequently and diligently recorded — from the 1980s onwards, its roots were planted firmly in earlier decades.

\section{REFERENCES}

Centraal Bureau voor de Statistiek. (2019). One-quarter of young adults are overweight. Retrieved from https://www.cbs.nl/en-gb/news/2019/15/one-quarter-of-young-adults-are-overweight

Devaux, M., Sassi, F., Church, J., Cecchini, M., \& Borgonovi, F. (2011). Exploring the relationship between education and obesity. OECD Journal: Economic Studies, 1, 121-159. doi: 10.1787/eco_studies2011-5kg5825v1k23

Komlos, J., Breitfelder, A., \& Sunder, M. (2009). The transition to post-industrial BMI values among US children. American Journal of Human Biology, 21(2), 151-160. doi: 10.1002/ajhb.20806

Mandemakers, K. (2019). Male kin heights database, part of the HSN dataset Heights and Life Courses, release: 2019.05 [Data set].

Staub, K., Rühli, F. J., Woitek, U., \& Pfister, C. (2010). BMI distribution/social stratification in Swiss conscripts from 1875 to present. European Journal of Clinical Nutrition, 64, 335-340. doi: 10.1038/ejcn.2010.7

Templin, T., Hashiguchi, T. C. O., Thomson, B., Dieleman, J., \& Bendavid, E. (2019). The overweight and obesity transition from the wealthy to the poor in low- and middle-income countries: A survey of household data from 103 countries. PLoS Medicine, 16(11): e1002968. doi: 10.1371/journal. pmed.1002968

van Wieringen, J. C. (1972). Seculaire groeiverschuiving: Lengte en gewicht surveys 1964-1966 in Nederland in historisch perspectief (Doctoral dissertation, Leiden University).

World Health Organization. (2020). Obesity and overweight. Retrieved from https://www.who.int/newsroom/fact-sheets/detail/obesity-and-overweight 